\title{
ERRATUM
}

\section{Erratum to: Video observation of an eel in the Anguilla japonica spawning area along the West Mariana Ridge}

\author{
Katsumi Tsukamoto $\cdot$ Noritaka Mochioka $\cdot$ \\ Michael J. Miller · Sumihiro Koyama • \\ Shun Watanabe $\cdot$ Jun Aoyama
}

Published online: 9 July 2013

(C) The Japanese Society of Fisheries Science 2013

Erratum to: Fish Sci (2013) 79:407-416

DOI 10.1007/s12562-013-0611-z

In the original publication of this article, Fig. 5 caption should read as given below:

Fig. 5 Photographs showing Nessorhamphus $(37.8 \mathrm{~cm})(\mathbf{a})$, Derichthys $(24.1 \mathrm{~cm})$ (b), a male Anguilla japonica spawning-condition eel $(58.5 \mathrm{~cm})(\mathbf{c})$, and a male Anguilla marmorata $(45.7 \mathrm{~cm})(\mathbf{d})$, all of which were caught by pelagic trawls $[3,4,5]$ in the spawning area region. Photos: Fisheries Agency, Japan (a, b), Fisheries Research Agency $(\mathbf{c}, \mathbf{d})$

The online version of the original article can be found under doi:10.1007/s12562-013-0611-z.

K. Tsukamoto $(\varangle) \cdot$ M. J. Miller · S. Watanabe $\cdot$ J. Aoyama Atmosphere and Ocean Research Institute, The University of Tokyo, Kashiwa, Chiba 277-8564, Japan

e-mail: ktpc@aori.u-tokyo.ac.jp

N. Mochioka

Bioresource Sciences, Faculty of Agriculture,

Kyushu University, Fukuoka, Fukuoka 812-8581, Japan

\section{S. Koyama}

Institute of Biogeosciences, Japan Agency for Marine-Earth

Science and Technology, 2-15 Natsushima-cho, Yokosuka,

Kanagawa 237-0061, Japan 